\title{
As tramas de uma complexa rede: atores e atrizes da política de direitos reprodutivos
} no Brasil

\author{
Jorge Lyra' ${ }^{1}$ (iD) 0000-0002-5381-2059 \\ Benedito Medrado Dantas ${ }^{1}$ (iD) 0000-0002-1085-5024 \\ 'Universidade Federal de Pernambuco, Centro de Filosofia e Ciências Humanas, \\ Departamento de Psicologia, Programa de Pós-Graduação em Psicologia \\ 50740-550-pospsicologiaufpe@gmail.com
}

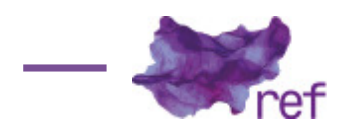

Resumo: Este estudo buscou identificar, a partir do referencial feminista, atores e atrizes envolvidos/as na política nacional de direitos sexuais e direitos reprodutivos em curso no Brasil. A escolha dessa política como lócus de investigação se deu em função de ser um espaço de discussão teórica e política com trajetória histórica de pelo menos trinta anos no campo da saúde, protagonizado por diferentes e diversos atores sociais em um campo de conhecimento e práticas ancorado em elementos considerados masculinos: a área biomédica e a de formulação das políticas. Com base em um Modelo Operacional de Análise de Políticas Públicas proposto por Araújo Júnior (2000), identificamos contexto, atores, processos e conteúdo da referida política tendo como ponto de partida os diálogos com 23 profissionais que, durante o período-foco da pesquisa (Gestão 2003-2006), ocuparam lugares importantes na formulação e debate público neste campo.

Palavras-chave: Análise de Políticas; Gênero e saúde; Política de direitos reprodutivos no Brasil

The Woof of a Complex Network: Actor and Actresses of the Reproductive Rights Policy in Brazil

Abstract: This study sought to identify, from the feminist framework, actors and actresses involved / in the national policy on sexual and reproductive rights, underway in Brazil. The choice of this policy as a place of research was due to be a theoretical discussion of space and politics with historical trajectory of at least thirty years in the field of health, carried out by different and diverse social actors in a field of knowledge and practices anchored in considered masculine elements: biomedical and formulation of policies. Based on an Operational Model Analysis of Public Policy proposed by Araújo Junior (2000), identified context, actors, process and content of the policy taking as a starting point the dialogue with 23 professionals who, during the research focus (management 2003-2006), occupied important places in the formulation and public debate in this field.

Keywords: Policy Analysis; Gender and health; Reproductive rights policy in Brazil

Ao focar a memória, história e política no campo de estudos sobre análise de políticas torna-se cada vez mais relevante e atual este artigo ao levarmos em consideração o contexto de desmonte das proposições de políticas públicas desenvolvidas tanto pelos movimentos sociais como pelos governos democráticos nos últimos anos no Brasil.

Este texto apresenta, assim, as reflexões sobre os atores ${ }^{1}$ envolvidos na política nacional de direitos sexuais e direitos reprodutivos no Brasil e, mais particularmente, suas compreensões sobre as noções de masculinidades construídas nessa política e os lugares atribuídos aos homens nos debates, propostas e recomendações. Iniciamos relembrando os percursos que realizamos ao

\footnotetext{
${ }^{1}$ Ao adotarmos a perspectiva feminista de análise insistimos na explicitação da participação intensa e diversa de homens e de mulheres neste processo, ou seja, atores, mas também atrizes, muitas vezes subsumidos em termos genéricos, como o próprio conceito de "atores" ora empregado.
} 
adentrar esse campo de política através dos quais identificamos os atores por meio das referências aos interlocutores explícitos e implícitos presentes nos discursos das entrevistas que realizamos, bem como nos documentos de governo referidos nos depoimentos.

\section{Notas metodológicas}

Nossa análise da Política Nacional de Direitos Sexuais e Direitos Reprodutivos no Brasil (Gestão 2003-2006) tomou como ponto de partida os diálogos com profissionais que, durante o período-foco da pesquisa, ocuparam lugares importantes na formulação e debate público neste campo.

Todos/as os/as profissionais entrevistados/as, no momento da pesquisa, tinham trajetória de inserção na área há mais de dez anos, o que nos permitiu também, a partir desses diálogos, construir uma retrospectiva histórica de consolidação deste campo² (Pierre BOURDIEU, 1983), bem como identificar focos, lugares, documentos de referência, tensões e atores que caracterizam o contexto desta política.

O discurso dos entrevistados condensa posições de entidades, grupos ou setores que compõem este campo. Eles falam a partir dos seguintes campos: movimento feminista, pesquisadores, redes políticas dos movimentos sociais, gestores, sistema das Nações Unidas, ${ }^{3}$ setor médico, ONGs que trabalham com a temática das masculinidades, campo jurídico, campo de análise do legislativo, sanitaristas, demógrafos e campo do debate sobre planejamento familiar ${ }^{4}$ (BRASIL, 2007).

A cada entrevista realizada, identificávamos um novo conjunto de interlocutores a entrevistar e uma série de documentos para leitura e análise. Assim, chegamos ao total de 23 entrevistas semiestruturadas (Odette G. PINHEIRO, 1999) com interlocutores privilegiados, por terem tomado parte, de forma direta ou indireta, ${ }^{5}$ no processo de formulação da política nacional de direitos reprodutivos vigente, à época, no Brasil.

Apresentamos no quadro 1 uma síntese com a descrição dos/as entrevistados/as.

Quadro 1 - Descrição geral dos/as entrevistados/as

\begin{tabular}{|l|l|l|l|}
\hline \multicolumn{1}{|c|}{ Sexo } & \multicolumn{1}{|c|}{ Idade } & \multicolumn{1}{|c|}{$\begin{array}{c}\text { Nivel de } \\
\text { escolaridade }\end{array}$} & $\begin{array}{c}\text { Tempo de formaç̃o } \\
\text { e de atuação na } \\
\text { área }\end{array}$ \\
\hline $\begin{array}{l}\text { Masculino: 05 } \\
\text { Feminino: } 18\end{array}$ & $\begin{array}{l}\text { Minima: 35 anos } \\
\text { Máxima: } 77 \text { anos }\end{array}$ & $\begin{array}{l}\text { Doutorado: 12 } \\
\text { Mestrado: 6 } \\
\text { Nivel superior em } \\
\text { Medicina: 3 } \\
\text { Professor livre- } \\
\text { docente: 1 } \\
\text { Professor titular: 1 }\end{array}$ & $\begin{array}{l}\text { Minimo: 14 anos } \\
\text { Máximo: 53 anos }\end{array}$ \\
\hline
\end{tabular}

Em relação às áreas de formação, observa-se vasta diversidade. Há profissionais da Antropologia, Sociologia, Psicologia Social, História, Filosofia, Direito, Enfermagem e Medicina. As áreas de interesse também são diversas: clínica médica; endocrinologia e reprodução humana; enfermagem obstétrica; gineco-obstetrícia; políticas públicas, gênero e saúde; saúde reprodutiva e gênero; socialização de gênero; gênero, sexualidade e saúde; direitos humanos, saúde, direitos sexuais e reprodutivos; e três pessoas apontaram o campo de saúde da mulher. Nos quadros $2 a$ e 2b apresentamos breve descrição dos/as entrevistados/as.

\footnotetext{
2 Entendemos campo a partir de Pierre Bourdieu (1983, p. 89) como "espaços estruturados de posições cujas propriedades dependem das posições nestes espaços, podendo ser analisadas independentemente das características de seus ocupantes [...] é preciso que haja objetos de disputas e pessoas prontas para disputar o jogo, dotadas de habitus que impliquem no conhecimento e reconhecimento das leis imanentes do jogo, dos objetos de disputas etc.".

${ }^{3}$ Entende-se o sistema das Nações Unidas como "as agências específicas (OMS, OIT, UNESCO) e o sistema financeiro consolidado na reunião de Bretton-Woods (o Banco Mundial e os bancos regionais de desenvolvimento, como o BID, Banco Interamericano) etc." (Peter SPINK, 1999, p. 147, nota 20). Neste estudo entrevistamos uma pessoa que foi do Fundo de População das Nações Unidas (UNFPA), e várias outras que têm participado de atividades promovidas pela ONU.

${ }^{4}$ Ao final de quatro anos de governo, foi interessante observar no Relatório de Gestão (BRASIL, 2007) o surgimento de um novo termo, planejamento reprodutivo, outra concepção, ou talvez mais uma variação das nomeações de como se compreende a política.

${ }^{5}$ Fazemos a ressalva quanto à participação direta ou indireta dos entrevistados no processo de formulação, pois consideramos que essa atuação não se restringe à escrita direta de um documento formal de política, mas abrange situações que envolvem a formulação de teorias, concepções, propostas em artigos científicos, disseminação de ideias em eventos, lugares de representação de atores envolvidos na política tanto em sua defesa como em contraposição à mesma.
} 
Quadro 2a - Descrição individual dos/as entrevistados/as $\mathbf{N}^{*} \quad$ Breve apreeentaglio

1. Pesquisadora sobre o tema ginero e feminismo, com estudos sobre o papel das agências de cooperaçalo e das instituiçổes do sistema ONU nas políticas de gênero; feminista; tem experiência de 34 anos de trabalho no campo.

2. Feminista; médica; possui experiência de 30 anos de trabalho no campo; coondenadora de uma das redes políticas feministas nacionais que já vem trabalhando há 24 anos com direitos sexuais e direitos reprodutivos.

3. Feminista; uma das fundadoras de uma ONG com mais de 20 anos de história; reconhecida internacionalmente no campo dos direitos reprodutivos; tem experiência de 30 anos de trabalho neste campo.

4. Participa das discussōes sobre o sistema ONU na temática de violência de gênero; especialista no debate sobre o campo juridico a partir da perspectiva de gênero e feminista; feminista; tem experiência de 38 anos de traballbo no campo.

5. Feminista; possui experiência de 28 anos de trabalho no campo; ex-coordenadora da área técnica de saudde da mulher em nível federal.

6. Médico ginecologista; tem experiência de 53 anos de trabalho no campo; participa há 33 anos de debates páblicos sobre o tema da saúde da mulher; professor-pesquisador especialista em saúde da mulher; integra a Federaçăo de Gineco-Obstetricia internacional.

7. Feminista; tem experiencia de 32 anos de trabalho no campo; participou ativamente dos processos das Conferências de Popalaçăo e da Mulher da ONU; integrante de redes feministas internacionais; trabalha com a questilo da sexualidade e AIDS.

8. Especialista no debate sobre o campo juridico a partir da perspectiva de gênero e feminista; feminista; tem experiencia de 20 anos de trabalho no campo.

9. Feminista; pesquisadora sobre o tema de mulheres e familias a partir da perspectiva de gênero e feminista; possui experiência de 37 anos de trabalho no campo; fez parte do comite de um programa de treinamento sobre Direitos Reprodutivos.

10. Jornalista, com doutorado em psicologia do desenvolvimento; atua no campo há 20 anos $\mathrm{e}$ fundou uma ONG que trabalha com homens e masculinidades, a partir da perspectiva de gênero, mas com poaca interface com o feminismo.

11. Ex-coordenadora do escritório no Brasil de uma instituiçalo internacional que financioa projetos no campo de direitos sexuais e direitos reprodutivos no Pás, inclusive sobre homens e masculinidades; tem experietncia de 23 anos de traballo no campo.

12. Feminista; médica sanitarista; possui experiência de 31 anos de trabalho no campo dos direitos reprodutivos; coordenoa a elaboraçăo do Programa de Atençāo Integral à Salude da Mulher (PAISM), em 1983.

Quadro 2b - Descrição individual dos/as entrevistados/as \begin{tabular}{|c|c|}
\hline $\mathbf{N}^{*}$ & Breve apresentaçăo \\
\hline 13. & Participou da implementação do PAISM no Nordeste; pesquisadora sobre o tema da
\end{tabular}

13. Participou da implementação do PAISM no Nordeste; pesquisadora sobre o tema da
saúde da mulher; enfermeira obstétrica; tem experiência de 30 anos de trabalho no campo.

14. Ex-coordenadora da área técnica de saúde da mulher em nível municipal e federal; feminista; faz parte de uma instituição feminista histórica; tem experiência de 28 anos de trabalho no campo.

15. Feminista; possui experiência de 30 anos de trabalho no campo; atualmente, ocupa cargo de gestão pública na área de políticas para mulheres.

16. Feminista; uma das fundadoras de uma $\mathrm{ONG}$ que trabalha com análise de políticas para as mulheres e feminista no campo do legislativo, há 20 anos.

17. Pesquisadora sobre o tema de homens a partir da perspectiva de gênero e feminista com um estudo no qual analisou o lugar dos homens nas Confere̊ncias da ONU; trabalhou em um órgão do sistema ONU; feminista; tem experiência de 28 anos de trabalho no campo.

18. Pesquisadora sobre o tema de direitos reprodutivos e humanização do parto; feminista; faz parte de uma instituição feminista histórica; tem realizado pesquisa sobre masculinidades; possui experiência de 24 anos de trabalho no campo.

19. Professor-pesquisador especialista em saúde da mulher; tem participado há vários anos dos debates públicos sobre o tema; médico; tem experiência de 35 anos de trabalho no campo; participa há vánios anos dos debates públicos sobre o tema da saúde da mulher; integrante da Federação de Gineco-Obstetrícia.

20. Psicóloga social, tem experiência de 30 anos de trabalho no campo; coordenadora de uma instituição internacional que financiou projetos no campo de direitos sexuais e direitos reprodutivos no Brasil, inclusive sobre homens e masculinidades.

21. Psicólogo social; tem experiência de 14 anos de trabalho no campo; foi um dos fundadores de uma ONG que trabalha com homens e masculinidades a partir da perspectiva feminista; pesquisa o tema de homens e masculinidades com base na perspectiva de gênero.

22. Representante da instituiçăo que foi referida como tendo participado das experiências de controle de natalidade no Brasil; médico; possui experiência de 30 anos de trabalho no campo; definiu-se como coordenador de uma ONG que atualmente segue a agenda politica feminista.

23. Ex-coordenadora no Brasil de uma instituição internacional que financia projetos no campo de direitos sexuais e direitos reprodutivos, inclusive sobre homens e masculinidades; pesquisadora sobre o tema de masculinidades a partir da perspectiva de gênero; tem experiência de 20 anos de trabalho no campo. 
Além disso, como parte do material empírico, foram igualmente analisados dez documentos prioritários, escolhidos entre os 46 documentos referidos pelos entrevistados, especificamente os que foram formulados e publicados pela gestão propriamente dita, durante o período-foco de nossa investigação (2003-2006), listados de acordo com o código no quadro 3.

Quadro 3 - Relação de documentos de governo analisados

\begin{tabular}{|c|c|}
\hline $\mathbf{N}^{\circ}$ & Títulos ( $\left.{ }^{*}\right)$ \\
\hline 1. & Politica Nacional de Atenção Integral à Saúde da Mulher - Principios e Diretrizes \\
\hline 2. & Politica Nacional de Atenção Integral à Saúde da Mulher - Plano de Ação 2004-2007 \\
\hline 3. & $\begin{array}{l}\text { Relatório de gestão } 2003 \text { a 2006: Política Nacional de Atençẫo Integral à Saúde da } \\
\text { Mulher }\end{array}$ \\
\hline 4. & Direitos Sexuais e Direitos Reprodutivos: uma prioridade do governo \\
\hline 5. & Cartilha sobre Direitos Sexuais, Direitos Reprodutivos e Métodos Anticoncepcionais \\
\hline 6. & Anticoncepção de emergência: perguntas e respostas para profissionais de saúde \\
\hline 7. & Atençã̃o humanizada ao abortamento - Norma técnica. \\
\hline 8. & Pré-Natal e Puerpério: Atenção Qualificada e Humanizada - Manual Técnico \\
\hline 9. & $\begin{array}{l}\text { Prevenção e tratamento dos agravos resultantes da violência sexual contra mulheres e } \\
\text { adolescentes - Norma técnica }\end{array}$ \\
\hline 10. & $\begin{array}{l}\text { Aspectos juridicos do atendimento às vitimas de violência sexual: perguntas e respostas } \\
\text { para profissionais de saúde }\end{array}$ \\
\hline
\end{tabular}

(*) Documentos disponibilizados pela Editora do Ministério da Saúde: http://dtr2001.saude.gov.br/ editora/produtos/livros/genero/livros.htm.

Os documentos são importantes dispositivos de análise de políticas públicas (SPINK, 1999) e constituem, conforme José Luiz ARAÚJO JUNIOR (2000, p. 96) e Araújo Junior e Romulo MACIEL FILHO (2001), um conjunto diverso de dados: "Estes dados podem incluir registros públicos, relatórios de governo, textos de jornais ou scripts de televisão, documentos privados, cartas e diários pessoais, memórias e entrevistas transcritas".

Em seguida, apresentaremos e discutiremos uma breve explanação dos resultados deste estudo focando os atores, como dito anteriormente, a partir dos quatro eixos que orientam o modelo operacional para análise de políticas de saúde proposto por José Luiz de Araújo Júnior (2000): contexto da política, atores envolvidos, processo da política e conteúdo.

\section{Fios, pontos e nós: a diversidade dos atores da política}

Entendemos os atores de uma política como todas as pessoas, instituições e organizações sociais que contribuem, direta ou indiretamente, para a mesma, considerando-se nesse cenário inclusive o controle social ou mesmo os que atuam em oposição à política. Assim, os atores constituíram nós das tramas ${ }^{6}$ de uma complexa rede, na qual se configuram jogos de poder e posições que, em disputa, definem sujeitos, lugares e direitos em uma política pública.

Desse modo, seguindo as recomendações de Araújo Júnior (2000), realizamos as seguintes etapas de análise:

1. identificação dos principais atores;

2. observação de suas posições em relação à política e seus graus de mobilização;

3. análise da correlação de forças entre eles e as possíveis alianças e confrontos.

Na primeira etapa, merece ser destacado que identificamos uma vasta quantidade e diversidade de atores nas entrevistas. Para ilustrar a diversidade de atores que são referidos nos documentos analisados, basta a leitura, por exemplo, de um trecho da Política Nacional de Atenção Integral à Saúde da Mulher - Princípios e Diretrizes:

[...] a Área Técnica buscou a parceria dos diferentes departamentos, coordenações e comissões do Ministério da Saúde. Incorporou as contribuições do movimento de mulheres, do movimento de mulheres negras e de trabalhadoras rurais, sociedades científicas, pesquisadores e estudiosos da área, organizações não governamentais, gestores do SUS e agências de cooperação internacional. Por fim, submeteu a referida Política à apreciação da Comissão Intersetorial da Mulher, do Conselho Nacional de Saúde. Trata-se, portanto, de um documento legitimado por

\footnotetext{
' Entre os sentidos de trama apresentados no Dicionário Houaiss da língua portuguesa (2001), dois deles fazem referência direta ao uso que estamos propondo neste texto: "estrutura de elementos que se cruzam e interligam como se formassem uma rede" e "o que constitui o fundo, a ligação de algo organizado".
} 
diversos setores da sociedade e pelas instâncias de controle social do Sistema Único de Saúde (SUS) (BRASIL, 2004, p. 5).

Na identificação dos atores, chegamos a um total de 200 referências, eliminando as repetições, que foram agrupadas em 11 categorias, conforme mostra o quadro 4.

Quadro 4 - Atores e atrizes identificadas/os nas entrevistas e nos documentos analisados, organizados em categorias

\begin{tabular}{|c|c|}
\hline Atores/atrizes & Deserição \\
\hline $\begin{array}{l}\text { Mulberes e } \\
\text { feministas }\end{array}$ & $\begin{array}{l}\text { Mulberes e entidades que se identificam a partir do Feminismo e/ou do } \\
\text { movimento de mulheres e que naio desenvolvem apōes diretas com } \\
\text { homens e/ou sobre masculinidades. }\end{array}$ \\
\hline $\begin{array}{l}\text { Outros ativistas } \\
\text { sociais * }\end{array}$ & $\begin{array}{l}\text { Pessons e entidades vinculadas a outros movimentos sociais } \\
\text { organizados, especialmente movimento sanitarista, movimento por } \\
\text { direitos humanos, movimento estudantil, movimento negro, movimento } \\
\text { pela humanizaçäo do parto e movimeato gay. }\end{array}$ \\
\hline $\begin{array}{l}\text { Profissionais de } \\
\text { medicina e direito* }\end{array}$ & $\begin{array}{l}\text { Inclui referéncia a atores identificados a partir de sua inserção } \\
\text { profissional, especialmente profissionais da medicina e entidades ou } \\
\text { profissionais do campo juridico. }\end{array}$ \\
\hline Legisladores * & $\begin{array}{l}\text { Pessoas ou entidades vinculadas ao Poder Legislativo, portanto, } \\
\text { referentes ao contexto de formulaçẵo e revisåo de politicas. }\end{array}$ \\
\hline Partidos politicos * & $\begin{array}{l}\text { Pessoas ou grupos identificados a partir da referểncia político- } \\
\text { partidária. }\end{array}$ \\
\hline Gestores públicos" & $\begin{array}{l}\text { Pessoas que atuam ou atuaram na gestĩo pública, em nivel local ou } \\
\text { nacional, bem como setores ou entidades vinculadas à gestảo pública. }\end{array}$ \\
\hline $\begin{array}{l}\text { Produtores de } \\
\text { conhecimento* }\end{array}$ & $\begin{array}{l}\text { Pessoas elou instituiçōes vinculadas à prodaç̃̃o acadêmica de pesquisa } \\
\text { nacional ou internacional. Inclui tanto universidades como centros de } \\
\text { pesquisa năo acadêmicos. }\end{array}$ \\
\hline $\begin{array}{l}\text { Instituiçōes } \\
\text { internacionais }\end{array}$ & $\begin{array}{l}\text { Orgãos vinculados às Nações Unidas, organismos bilaterais de } \\
\text { cooperaçăo internacional, financiadoras de grande porte e abrangẻncia } \\
\text { internacional. }\end{array}$ \\
\hline Midia & $\begin{array}{l}\text { Pessoas ou grupos identificados a partir da referẻncia aos mejos de } \\
\text { comunicaçăo de massa. }\end{array}$ \\
\hline Religiosos ${ }^{*}$ & Grupos ou representantes de setores religiosos. \\
\hline $\begin{array}{l}\text { Homens, malheres e } \\
\text { grupos que } \\
\text { trabalham com } \\
\text { homens }\end{array}$ & $\begin{array}{l}\text { Inclui referẻncias diretas aos nomes de bomens que atuam no campo } \\
\text { dos direitos sexuais e reprodutivos, bem como entidades feministas que } \\
\text { trabalham com homens elou instituipōes e pessoas que trabalham com } \\
\text { os bomens, mas não se identificam a partir do feminismo. }\end{array}$ \\
\hline
\end{tabular}

(*) As categorias formuladas no masculino seguem o padrão adotado no discurso das entrevistadas e dos entrevistados.

Em nossa análise, não nos interessou identificar diretamente a frequência com que os atores eram referidos nem a diversidade de termos e expressões empregados nas falas e documentos. Nosso foco recaiu, sobretudo, no uso discursivo dos atores na construção argumentativa dos entrevistados, com o objetivo de identificar, seguindo Araújo Júnior (2000), posições em relação à política, bem como graus de mobilização de atores genéricos (tomados em categorias e não como indivíduos), a correlação de forças entre eles e as possíveis alianças e confrontos.

Para tanto, construímos uma "compreensão analítica", articulando os discursos dos entrevistados com as reflexões teóricas que discutem a inserção dos homens neste campo. Vale ressaltar que os argumentos, narrativas e outros recursos discursivos foram importantes elementos para construção da análise sobre os demais componentes da política (contexto, processo e conteúdo). Assim, a análise acerca dos atores se torna mais rica a partir da leitura dos demais componentes, na medida em que estão plenamente integrados. ${ }^{7}$ Interessou-nos, aqui, identificar tão somente, como dito acima, graus de mobilização e posições de poder a partir de uma compreensão panorâmica.

Em nossas interpretações e análises, consideramos atores os interlocutores "de segunda mão", ou seja, aqueles e aquelas que, no diálogo entre entrevistador e entrevistados, foram referidos como pessoas ou instituições que, em confrontos e alianças, participaram direta ou indiretamente da construção de possibilidades ou obstáculos à inserção dos homens como sujeitos na construção das políticas de direitos reprodutivos.

Nas falas e documentos analisados há uma forte referência a representantes feministas e ao movimento feminista e de mulheres como importantes atores (ou atrizes) na construção da

\footnotetext{
${ }^{7}$ Para ver a análise em detalhes, consultar tese completa.
} 
política em foco. Referências a nomes próprios, grupos e movimentos foram frequentes nas falas dos entrevistados, bem como na própria redação de alguns documentos.

No processo de análise, em consonância com a revisão da literatura e alguns trabalhos com os quais dialogamos neste texto (Maria Teresa CITELI, 2005; Sonia CORRÊA, 2002; Laura MOUTINHO; Sérgio CARRARA; Silvia AGUIÃO, 2005), é evidente a relevância e alto grau de mobilização do movimento feminista e de mulheres no campo de formulação e implementação de políticas de direitos reprodutivos no período analisado.

\section{Mulheres e feministas}

Para entendermos a posição das mulheres e feministas em relação à política, de antemão, precisamos considerar, segundo os entrevistados, que estamos falando de um movimento social plural. Em primeiro lugar, nem todo movimento de mulheres pode ser considerado feminista, pois este último tem como base uma posição política que não necessariamente faz parte da trajetória ou identidade de todo o movimento de mulheres. Além disso, o próprio movimento feminista é compreendido a partir de concepções multifacetadas de feminismos que se fazem presentes nesses espaços de discussão e ação política.

Embora, por vezes, o movimento de mulheres e o feminismo sejam tomados, em algumas falas, como obstáculo ou resistência à inclusão dos homens como sujeitos de direitos reprodutivos, por outro lado, na maioria das falas, reconhece-se que as políticas de direitos reprodutivos no Brasil são uma conquista do movimento feminista e de mulheres e que, portanto: 1) pensar hoje sobre a inserção dos homens nesse campo seria uma consequência das conquistas feministas; e 2) a plena efetivação do ideário feminista remeteria a uma mudança na vida não apenas das mulheres, mas também das instituições e dos próprios homens. Assim, a perspectiva em relação à participação ou não dos homens nesse contexto é diversa, não há consenso, pois está baseada em compreensões distintas sobre os homens, o masculino e as relações de poder.

\section{Outros ativistas sociais}

Além do movimento feminista, expressivamente aludido nas falas e referenciado nos documentos, encontramos um conjunto de atores, aqui identificados como outros ativistas sociais, vinculados a movimentos sociais diversos que, segundo os entrevistados, colaboram para o fortalecimento do campo dos direitos reprodutivos no Brasil: movimento de direitos humanos, movimento sanitarista, movimento estudantil, movimento negro, movimento pela humanização do parto e movimento gay.

De acordo com os entrevistados, esses ativistas (incluindo pessoas e grupos), em seu conjunto, colocam-se de forma diferente em relação ao debate sobre homens, masculinidades e políticas públicas em direitos reprodutivos. Eles apresentam interesses, configurações, trajetórias e histórias particulares que se diferenciam do movimento feminista e não possuem o mesmo grau de mobilização e influência direta, embora colaborem a partir de ações integradas ou do compartilhamento de princípios e conceitos.

\section{Profissionais de Medicina e Direito}

Os profissionais de Medicina e Direito são também identificados entre os atores da política nacional de direitos sexuais e direitos reprodutivos no Brasil. São considerados, por alguns entrevistados, como aliados estratégicos no processo de formulação e implementação de políticas de diretos sexuais e reprodutivos, na medida em que possuem conhecimento técnico e poder (especialmente a partir das entidades e redes que representam suas categorias profissionais) que favorecem a formulação de propostas e normas técnicas das políticas (Anibal FAÚNDES; Ellen HARDY; José A. PINNOTI, 1989; Cristião F. ROSAS, 2005). Por outro lado, esses mesmos atores são vistos, em outros momentos, como obstáculos para a implementação das políticas, na medida em que sua formação e cotidiano de trabalho são marcados pela hegemonia masculina, na qual o conceito de direitos reprodutivos, a partir do viés de gênero, raramente é discutido.

No que diz respeito ao campo do direito, por se tratar de um campo em princípio conservador (tendendo mais à manutenção do que à transformação), contradições também se fazem presentes. Por outro lado, as análises de casos e estratégias do discurso e das instâncias do campo jurídico sempre foram ferramentas fundamentais para a defesa da democracia e da liberdade, desde a época da ditadura. Foram mencionados, ainda, debates mais recentes em torno da anencefalia, que remetem à questão do aborto e às pesquisas com células-tronco, bem como à discussão sobre tecnologias reprodutivas que têm sido campos de pesquisa, reflexão e ação de alguns dos entrevistados. Em todos esses campos de debate, os entrevistados apontam que ainda é tímida a discussão sobre os homens ou as masculinidades (Margareth ARILHA, 2007; Debora DINIZ, 2007; 2008). 


\section{Legisladores e Partidos Políticos}

Além dos profissionais de Medicina e de Direito, identificamos, nas entrevistas e documentos, referências a legisladores e partidos políticos como importantes atores envolvidos na política nacional de direitos sexuais e direitos reprodutivos no Brasil.

Esses dois atores foram considerados estratégicos pelos entrevistados, a partir da concepção que a maioria destes tem sobre saúde, entendida como um direito do cidadão e da cidadã que deve ser garantido pelo Estado e pelo qual se deve reivindicar. Nesse sentido, há forte influência dos atores ligados ao campo do Legislativo, bem como assumem grande relevância pessoas e grupos vinculados aos partidos políticos sob o Executivo.

É interessante perceber, contudo, que no decorrer dos anos, e mais recentemente, esses atores, que foram aliados políticos na época da ditadura e na construção da democracia no Brasil com o processo da Constituinte, têm sido um dos opositores da política atual de direitos reprodutivos e com forte influência das bancadas de deputados católicos, evangélicos e espíritas. A partir dos princípios fundamentalistas religiosos e culturais, vêm contribuindo com o retrocesso de direitos garantidos, segundo os entrevistados (Luiz Fernando D. DUARTE, 2005; Emerson GIUMBELLI, 2005).

\section{Gestores Públicos}

Entre os atores referidos, os gestores públicos também ocupam destaque nas falas dos entrevistados e nos documentos públicos. Resolvemos, em um primeiro momento, reorganizar os dados em diferentes níveis e instâncias de forma a garantir uma ordenação compatível com as funções e atribuições da própria gestão pública. Além de nomes diretos de presidentes, governadores, prefeitos e ministros, entre outros, foram lembradas também as políticas, programas, conselhos e comissões.

\section{Produtores de conhecimento}

Os entrevistados comentaram sobre a participação de algumas instituições que têm provocado o campo de conhecimento sobre o tema saúde, direitos reprodutivos e direitos sexuais (CITELI, 2005). Entre os atores aqui classificados como produtores de conhecimento, foram referidas algumas universidades, o Instituto Brasileiro de Geografia e Estatística, o Instituto de Pesquisa Econômica Aplicada (IPEA), a Associação Brasileira de Estudos Populacionais (ABEP) (Elza BERQUÓ; Maria Isabel B. ROCHA, 2005) e a Fundação Carlos Chagas (FCC). Foram destacados os papéis importantes do IBGE e do IPEA nas análises de dados diversos que subsidiam a formulação de políticas. No caso da ABEP, ressaltaram-se as tensões e os embates das discussões no campo da Demografia que durante um longo período histórico foram fundamentando os paradigmas nesse campo, inclusive o debate sobre os homens e direitos reprodutivos. A FCC foi apontada pelo seu papel estruturador do campo de estudos sobre mulher e relações de gênero, desde o início dos anos 1980, período sobre o qual falamos detalhadamente na parte sobre contexto e conteúdo (Cristina BRUSCHINI; Sandra UNBEHAUM, 2002).

\section{Instituições Internacionais}

Nas entrevistas, foram ainda mencionadas as distintas instituições e pessoas que classificamos como instituições internacionais, que compreendem uma diversidade de referências, desde o sistema ONU e agências de cooperação bilateral, até fundações, pessoas e instituições envolvidas com as políticas de controle de natalidade.

Nesse conjunto, os entrevistados destacaram a participação e influência da ONU e do ciclo de Conferências (referidas na análise do contexto) como importantes atores na defesa das propostas, mas também como um espaço múltiplo e diverso em que há tensões históricas em função dos usos "despolitizados" de conceitos, especialmente o conceito de gênero e direitos reprodutivos, além de acordos produzidos nesses espaços.

Como grandes fontes de recursos de projetos e políticas para o Brasil foram citados o Banco Mundial e a Agência Internacional de Desenvolvimento do Governo dos Estados Unidos (USAID). Contudo, a onda conservadora e fundamentalista, que já foi comentada em outros momentos, cria fortes embates na implementação de políticas, segundo alguns dos entrevistados, chegandose à situação crítica e elogiável por parte do governo brasileiro de recusar apoio de recursos às propostas para as políticas de AIDS em função das restrições impostas.

Os debates sobre as questões do controle de natalidade, planejamento familiar, saúde reprodutiva ou outros termos que os entrevistados usaram serão trazidos em toda a sua complexidade na análise do conteúdo da política. Essa é uma questão que sempre permeou esse campo de políticas, inclusive foi recorrente a nomeação de algumas instituições nessa categoria, como a BEMFAM (Alinne de L. BONETTI, 2007; Magda Fernanda M. FERNANDES, 2003). Quando o foco recai sobre os homens, foram citadas a Associação para a Contracepção Cirúrgica 
Voluntária $(A V S C)^{8}$ e a Promoção da Paternidade Responsável (PROPATER), que realizavam campanhas de vasectomia em vários países, incluindo o Brasil.

Foi relatada por alguns entrevistados a contribuição das Fundações MacArthur e Ford, mas apontado também que as alianças e disputas por apoio passavam pelas prioridades temáticas e políticas de cada Fundação, a depender do momento histórico, como o próprio entendimento do debate sobre os homens (CORRÊA; Peter MACINTYRE, 2003; Cecília de MELLO E SOUZA, 2002; Fúlvia ROSEMBERG, 1993).

\section{Mídia}

A mídia também foi identificada nessa análise dos atores, especialmente presente nas falas dos entrevistados. Essa referência aparece em duas direções. Por um lado, os instrumentos de mídia têm sido usados como ferramentas simbólicas para retratar e dar um maior alcance às transformações socioculturais. Por outro, a depender da "cabeça do publicitário" que formula, por exemplo, os comerciais de cerveja, automóveis ou margarina, terminam por promover retrocessos às propostas de políticas oriundas das gestões públicas ou mesmo de documentos de advocacy elaborados pela sociedade civil. A questão dos homens é um exemplo típico de mais um produto de mercado que tem sido colocado à venda para promover o uso de novos medicamentos que prometem garantir a saúde, a potência. Raramente se discute os homens a partir de outras perspectivas, e isso é válido também para as mulheres. Exceção à regra é a mídia alternativa, mas esta é produzida pelas próprias organizações não governamentais, como o Jornal Mulherio, que marcou uma época, mas atualmente não é mais publicado (Maria Thereza MONTENEGRO, 1992).

\section{Religiosos}

De aliado em épocas de outrora, em um momento muito delicado como a ditadura, a um dos grandes obstáculos à formulação e implementação de políticas públicas no campo da sexualidade e direitos reprodutivos, essa é a forma como os religiosos aparecem entre os atores que influenciam a política nacional de direitos reprodutivos no Brasil (Maria José F. ROSADONUNES, 1999). O embate mais frequente é com a lgreja Católica e seus representantes, mas também acontecem com cada vez mais intensidade disputas com as igrejas evangélicas e pastores, muitas vezes envolvidos em escândalos sexuais ou financeiros.

\section{Homens, mulheres e grupos que trabalham com homens}

Por último, destacamos os atores identificados nas falas dos entrevistados como homens, mulheres e grupos que trabalham com homens, a partir de diferentes estratégias (pesquisas, oferta de serviços, mobilização comunitária e/ou advocacy), focos temáticos (saúde reprodutiva, paternidade, diversidade sexual, violência de gênero) e fundamentos (feminista, de gênero, "autônomos").

Entre esses atores, identificamos três posições distintas: 1) nomes próprios de homens que têm atuado no campo dos Direitos Sexuais e Reprodutivos e que, de maneira pontual ou processual, têm produzido conhecimentos e ou práticas de saúde envolvendo a população masculina, isolados do debate feminista; 2) pessoas e entidades que têm desenvolvido pesquisas sobre os homens e o tema das masculinidades, empregando gênero como categoria analítica; e 3) entidades feministas e homens que assumem a matriz teórica e política feminista na abordagem de trabalho com os homens.

Os entrevistados reconhecem que esses atores têm contribuído de maneira significativa na construção de espaços de debate sobre o tema dos homens e das masculinidades, seja no campo da pesquisa, seja no campo das ações diretas com a população masculina ou na discussão sobre políticas públicas locais e nacionais, bem como no cenário internacional.

Contudo, um dos entrevistados, que se identificou como homem feminista, ressaltou que, apesar da complexidade do tema e da necessidade de uma leitura de gênero e feminista, infelizmente, a gestão pública tem se orientado exclusivamente por uma leitura instrumental e segmentada do problema, sintetizada na expressão "saúde do homem". Esta, segundo ele, pautase exclusivamente por uma leitura epidemiológica do problema e busca soluções técnicas, desconsiderando as matrizes culturais e de gênero. Em outras palavras, ele questiona: É possível transformar as relações de poder e dominação apenas oferecendo serviços visando à redução de agravos à saúde da população masculina?

\section{Tramas e nós cegos: articulações e disputas entre atores da política}

Adentrar esse cenário de políticas públicas é um desafio instigante e envolvente, pois as políticas são enredos com tramas complexas, que envolvem diversos campos de saber, bem como

\footnotetext{
${ }^{8}$ Em inglês: Association for Voluntary and Surgical Contraception.
} 
níveis distintos nos quais os fenômenos ocorrem (desde macroestruturais a micropolíticos) e atores/ atrizes nele implicados. Exige de quem está formulando, contestando, se beneficiando, ou mesmo analisando, como estamos fazendo neste artigo, uma autorreflexão sobre em que lugar nos colocamos nessa rede.

Diante dessa complexidade, adotar um modelo de análise de políticas que busca integrar diferentes aspectos é fundamental. A proposta de Araújo Júnior (2000) assinala a interconexão entre os componentes da ferramenta de análise por ele formulada. A apresentação dessas reflexões por partes separadas, em princípio, é apenas um recurso didático para tornar compreensível para o leitor os caminhos percorridos ou, para nos mantermos na metáfora da rede, para repassar os conhecimentos de como fizemos os alinhavos, os pontos e o nó. Um saber que é compartilhado para que a tessitura das redes não se perca no tempo.

Certamente, a identificação dos atores e atrizes envolvidos na política nos ajuda a entender os nós desta rede. Ao mesmo tempo, ao adotarmos a perspectiva feminista de análise, insistimos na explicitação da participação intensa e diversa de mulheres e de homens neste processo, mesmo com todas as controvérsias em relação aos homens (Benedito MEDRADO; Jorge LYRA, 2008). Em relação às mulheres, é interessante assinalar a presença efetiva das atrizes, muitas vezes subsumidas em termos genéricos, como o próprio conceito de "atores" ora empregado. Contudo, nos chamou atenção o fato de o genérico ter sido usado como referência tanto nos documentos como nas falas dos entrevistados, incluindo aqui as mulheres que se identificam a partir do feminismo.

Nas longas entrevistas iniciais, uma teia de relações começou a ser tecida ao perguntarmos quem eram os atores envolvidos com essa política. Além de levantarmos informações específicas sobre esse elemento que compõe as políticas, este também foi um guia na identificação das pessoas a serem entrevistadas posteriormente.

Voltando à metáfora da trama, observamos que as narrativas construídas pelos entrevistados nos apresentam e desvelam uma complexa rede de atores constituída de vários campos em constante movimento. Assinalamos que esses campos não são únicos e exclusivos; os atores falam de lugares imbricados, múltiplos e polissêmicos. A ordenação em categorias é apenas uma estratégia metodológica para auxiliar na compreensão da complexidade dos fenômenos, tendo um caráter meramente organizativo e didático.

Esse processo de formulação de sínteses visa, antes de mais nada, a uma aproximação progressiva com a questão de pesquisa que estamos trabalhando neste estudo. Nesse sentido, um olhar especial foi dado aos atores que contribuíram ou dificultaram, direta ou indiretamente, 0 debate sobre o lugar dos homens nestas políticas. Sendo assim, de acordo com as etapas de análise propostas por Araújo Júnior (2000), traçamos aqui uma breve descrição dos atores e procuramos apreender suas posições em relação à política e seus graus de mobilização, bem como compreender a correlação de forças entre eles e as possíveis alianças e confrontos.

\section{Chegamos assim às considerações finais...}

A análise de todo o material empírico evidencia, em linhas gerais, uma Política Pública de Direitos Sexuais e Direitos Reprodutivos no Brasil consolidada, pelo menos no plano da formulação, dos documentos de domínio público, apesar de recente e com vários campos de tensão em torno de problemas fundamentais. A diversidade profícua de documentos (entre resoluções, normas técnicas etc.) e o relato dos entrevistados apresentam o período analisado (primeira gestão do governo Lula - 2003-2006) como um momento de fortalecimento e reconhecimento público de pautas antes restritas à agenda dos movimentos sociais em defesa dos direitos reprodutivos das mulheres.

Em linhas gerais, o que se ressalta nas falas e documentos analisados é uma forte referência a representantes feministas e ao movimento feminista e de mulheres como importantes atores (ou atrizes) na construção da política em foco. O que observamos é que o debate em torno dos direitos das mulheres encontrou, na gestão analisada, o cenário ideal para fortalecimento de direitos adquiridos e ampliação de debates e conquistas. Por outro lado, a visibilidade pública das conquistas também tende a fortalecer posturas conservadoras, que exigem, por sua vez, uma permanente vigilância e intenso investimento de grupos sociais organizados, principalmente na atual conjuntura.

Após mais de cinquenta anos de incidência do movimento feminista na elaboração de políticas públicas, o que se observa no Brasil parece ser um desenvolvimento bastante significativo de políticas que buscam atender às necessidades específicas das mulheres em várias áreas, especialmente saúde, trabalho, violência. Porém, como ressalta o relatório de Gestão 2003-2006 da Política Nacional de Atenção Integral à Saúde da Mulher, "ainda há muito o que fazer em relação aos homens" no que se refere ao planejamento reprodutivo (BRASIL, 2007).

Nossas análises evidenciam que, nesta política, as masculinidades são pensadas, em geral, como dispositivos de opressão, e os homens como instrumentais ou sujeitos secundários, diante da 
trajetória histórica ainda incipiente de reflexões sobre os homens e as masculinidades no campo dos direitos reprodutivos, a partir do enfoque feminista e de gênero (MEDRADO; LYRA, 2008). A sensação é que os estudos sobre os homens estão (re)fazendo todo o percurso que as mulheres já fizeram, ou seja, parando somente agora para "escutar" e descrever o que os homens têm a dizer; iniciando do zero, sem problematizar estes próprios discursos a partir de uma leitura histórica.

Com certeza, não basta incluir ações, programas ou serviços. É preciso ter uma linha conceitual e política clara, afinal, as políticas são enredos com tramas complexas, na medida em que envolvem diversos e diferentes níveis nos quais os fenômenos ocorrem, campos de tensão e atores em disputa. Destacamos assim a necessidade de um posicionamento analítico e crítico a respeito do discurso sobre os homens no campo dos direitos sexuais e direitos reprodutivos tendo em vista o avanço do conhecimento neste campo formulado pelas feministas e por alguns homens que se identificam ou não como feministas. Infelizmente, o que temos percebido na maioria dos trabalhos sobre homens e masculinidades é uma tendência a investigações com caráter meramente descritivo que desconsideram a trajetória histórica das reflexões neste campo vindas do movimento de mulheres e feminista e também do movimento gay e lésbico. Concluímos este trabalho, porém, acreditando que podemos construir outros "roteiros" mais críticos e ousados sobre os homens e as masculinidades quando cremos na radicalidade que a perspectiva feminista pode nos oferecer com as contribuições e tensões produtivas nos diálogos e conflitos com os atores e atrizes que constituem essa complexa rede.

\section{Referências}

ARAÚJO JUNIOR, José Luiz A. C. Health sector reform in Brazil, 1995-1998: an health policy analysis of a developing health system. 2000. Thesis (PhD in Health Services Studies) - The University of Leeds, Leeds, Inglaterra.

ARAÚJO JUNIOR, José Luiz; MACIEL FILHO, Romulo. "Developing an Operational Framework for Health Policy Analysis". Revista Brasileira de Saúde Materno Infantil, v. 1, n. 3, p. 203-221, 2001.

ARILHA, Margareth. Saúde reprodutiva e sexualidade no Brasil: 25 anos de trajetória e perspectivas para o futuro. Trabalho submetido ao concurso Prêmio NEPO 25 anos, com o tema Saúde Reprodutiva e Sexualidade no Brasil: 25 anos de trajetória e perspectivas para o futuro, 2007. Disponível em: http://www.ccr.org.br/a_noticias_nepo.asp?indica=ok. Acesso em: 15/12/2007.

BERQUÓ, Elza; ROCHA, Maria Isabel B. "A ABEP no contexto político e no desenvolvimento da demografia nas décadas de 1960 e 1970". Revista Brasileira de Estudos Populacionais, São Paulo, v. 22, n. 2, p. 233-246, jul./dez. 2005.

BONETTI, Alinne de L. Não basta ser mulher, tem de ter coragem: uma etnografia sobre gênero, poder, ativismo feminino popular e o campo político feminista de Recife - PE. 2007. Tese (Doutorado em Ciências Sociais) - Instituto de Filosofia e Ciências Humanas, Universidade Estadual de Campinas, Campinas, Brasil.

BOURDIEU, Pierre. Questões de sociologia. Rio de Janeiro: Marco Zero, 1983.

BRASIL. Relatório de Gestão 2003 a 2006: Política Nacional de Atenção Integral à Saúde da Mulher. Ministério da Saúde. Secretaria de Atenção à Saúde. Departamento de Ações Programáticas Estratégicas. Área Técnica de Saúde da Mulher. Brasília, 2007.

BRASIL. Política Nacional de Atenção Integral à Saúde da Mulher: princípios e diretrizes. Secretaria de Atenção à Saúde. Departamento de Ações Programáticas Estratégicas. Área Técnica de Saúde da Mulher. Brasília, 2004.

BRUSCHINI, Cristina; UNBEHAUM, Sandra G. Gênero, democracia e sociedade brasileira. São Paulo: FCC; Ed. 34, 2002.

CITELI, Maria Teresa. A pesquisa sobre sexualidade e direitos sexuais no Brasil (1990-2002): revisão crítica. Rio de Janeiro: CEPESC, 2005.

CORRÊA, Sonia. "Gênero e saúde: campo em transição". In: BRUSCHINI, Cristina; UNBEHAUM, Sandra (org.). Gênero, democracia e sociedade brasileira. São Paulo: FCC; Ed. 34, 2002. p. 357-388.

CORRÊA, Sonia; MACINTYRE, Peter. Programa de População e Saúde Reprodutiva no Brasil:lições aprendidas. São Paulo: Fundação MacArthur, 2003.

DINIZ, Debora. "Aborto e saúde pública no Brasil”. Cadernos de Saúde Pública, Rio de Janeiro, v. 23, n. 9, p. 1992-1993, set. 2007. 
DINIZ, Debora. "Etnografia da infertilidade". Cadernos de Saúde Pública, Rio de Janeiro, v. 24, n. 1, p. 230-231, jan. 2008.

DUARTE, Luiz Fernando D. "Ethos privado e justificação religiosa: negociações da reprodução na sociedade brasileira". In: HEILBORN, Maria Luiza; DUARTE, Luiz Fernando D.; PEIXOTO, Clarice; BARROS, Myriam L. (org.). Sexualidade, família e ethos religioso. Rio de Janeiro: Garamond, 2005.

FAÚNDES, Anibal; HARDY, Ellen; PINOTI, José A. "Commentary on women's reproductive health: means or end?". International Journal of Gynecology and Obstetrics, London, v. 3, p. 115-1 18, 1989.

FERNANDES, Magda Fernanda M. "Mulher, família e reprodução: um estudo de caso sobre o planejamento familiar em periferia do Recife, Pernambuco, Brasil”. Cadernos de Saúde Pública, Rio de Janeiro, v. 19, n. 2, p. S253-S261, 2003.

GIUMBELLI, Emerson (org.). Religião e sexualidade: convicções e responsabilidades. Rio de Janeiro: Garamond, 2005.

MEDRADO, Benedito; LYRA, Jorge. "Por uma matriz feminista de gênero para os estudos sobre homens e masculinidades". Revista Estudos Feministas, Florianópolis, v. 16, n. 3, p. 809-840, dez. 2008.

MELLO E SOUZA, Cecília de. "Dos estudos populacionais à saúde reprodutiva". In: BROOKE, Nigel; WITOSHYNSKY, Mary (org.). Os 40 anos da Fundação Ford no Brasil: uma parceria para a mudança social. Rio de Janeiro: Fundação Ford; São Paulo: EDUSP, 2002. p. 131-164.

MONTENEGRO, Maria Thereza. Uma organização não-governamental feminista: O Mulherio. 1992. Dissertação (Mestrado em Psicologia Social) - Pontifícia Universidade Católica de São Paulo, São Paulo, Brasil.

MOUTINHO, Laura; CARRARA, Sérgio; AGUIÃO, Silvia (org.). Sexualidade e comportamento sexual no Brasil: dados e pesquisas. Rio de Janeiro: CEPESC, 2005.

PINHEIRO, Odette G. "Entrevista: uma prática discursiva". In: SPINK, Mary Jane (org.). Práticas discursivas e produção de sentidos no cotidiano: aproximações teóricas e metodológicas. São Paulo: Cortez, 1999.

ROSAS, Cristião F. "Política Nacional de Direitos Sexuais e Direitos Reprodutivos: rompendo velhos preconceitos e construindo novos paradigmas". Jornal da Rede Feminista de Saúde, Belo Horizonte, n. 27, p. 18-20, 2005.

ROSADO-NUNES, Maria José F. “Religion and women's rights: the fundamentalist face of catholicism in Brazil". Conscience, Washington, v. 20, n. 3, p. 25-30, 1999.

ROSEMBERG, Fúlvia. "Estudos sobre mulher e relações de gênero". In: MICELLI, Sérgio (org.). $A$ Fundação Ford no Brasil. São Paulo: FAPESP; Sumaré, 1993. p. 205-236.

SPINK, Peter. Análise de documentos de domínio público. In: SPINK, Mary Jane (org.). Práticas discursivas e produção de sentidos no cotidiano: aproximações teóricas e metodológicas. São Paulo: Cortez, 1999.

TRAMA. In: HOUAISS, Antonio. Dicionário eletrônico Houaiss da língua portuguesa. Rio de Janeiro: Objetiva, 2001. CD-ROM.

Jorge Luiz Cardoso Lyra da Fonseca (jorglyra@gmail.com) é doutor em Saúde Pública, professor do Departamento de Psicologia da UFPE (cursos de graduação e pós-graduação); coordenador do Núcleo Feminista de Pesquisas em Gênero e Masculinidades (Gema/UFPE) e um dos fundadores da ONG Instituto PAPAI.

Benedito Medrado Dantas (beneditomedrado@gmail.com) é doutor em Psicologia Social, professor do Departamento de Psicologia da UFPE (cursos de graduação e pós-graduação); coordenador do Núcleo Feminista de Pesquisas em Gênero e Masculinidades (Gema/UFPE) e um dos fundadores da ONG Instituto PAPAI. 


\section{COMO CITAR ESSE ARTIGO DE ACORDO COM AS NORMAS DA REVISTA}

LYRA, Jorge; MEDRADO, Benedito. "As tramas de uma complexa rede: atores e atrizes da política de direitos reprodutivos no Brasil". Revista Estudos Feministas, Florianópolis, v. 27, n. 1, e44803, 2019.

\section{CONTRIBUIÇÃO DE AUTORIA}

Os autores colaboraram igualmente na concepção, análise de dados, elaboração do manuscrito, redação e revisão do artigo, bem como aprovação da versão final do trabalho.

\section{FINANCIAMENTO}

Capes, via bolsa de Doutorado.

\section{CONSENTIMENTO DE USO DE IMAGEM}

Não se aplica

APROVAÇÃO DE COMITÊ DE ÉTICA EM PESQUISA

O projeto de tese foi submetido e aprovado pelo comitê de ética do Centro de Pesquisas Aggeu Magalhães (CPqAM-FIOCRUZ), em 20 de janeiro de 2006, protocolo nº0030.0.095.000-06.

\section{CONFLITO DE INTERESSES}

Não se aplica

\section{LICENÇA DE USO}

Este artigo está licenciado sob a Licença Creative Commons CC-BY. Com essa licença você pode compartilhar, adaptar, criar para qualquer fim, desde que atribua a autoria da obra.

\section{HISTÓRICO}

Recebido em 23/05/2016

Reapresentado em 02/05/2018

Aprovado em 04/05/2018 